\title{
Aortic Valve Replacement in Patients 70 Years and Older
}

\author{
Eduardo Salazar, M.D., Jorge Torres, M.D., Rodolfo Barragán, M.D., Mauricio LóPeZ, M.D., Luis Alberto LaSSES, M.D. \\ Instituto Nacional de Cardiología Ignacio Chávez, México City, México
}

\section{Summary}

Background: Aortic valvular disease is the most common valvular lesion among elderly patients. Because of changing demographics, it has become increasingly frequent. Aortic valve replacement (AVR) is the only effective treatment for aortic valvular disease.

Hypothesis: This study was undertaken to evaluate the results of AVR in an elderly population.

Methods: Data were retrospectively analyzed in 117 consecutive patients (mean age 73.8 years) who underwent AVR between 1991 and 2002.

Results: Pure or predominant severe aortic stenosis was present in 108 patients. Nine patients had severe aortic regurgitation. Before valve replacement, $62.4 \%$ of the patients were in New York Heart Association (NYHA) functional class III-IV. A bioprosthesis was implanted in $62.4 \%$ of the patients, and $37.6 \%$ received a mechanical valve. Concomitant cardiac surgical procedures were performed in 25 patients (coronary artery bypass graft in 22 , mitral valve replacement in 3 ). There were 17 deaths, giving a perioperative mortality rate of $14.5 \%$. Multivariate logistic regression showed that repeat surgery for bleeding, prolonged cardiopulmonary bypass time, postoperative respiratory failure, and postoperative acute renal insufficiency were significant independent predictors of operative mortality. Of the 100 hospital survivors, 78 were followed for a mean of 42.9 months. There were six deaths during followup; only two of these were cardiac related. Five-year actuarial survival for all patients and for hospital survivors were 70 and $91.1 \%$, respectively. One year post surgery, all patients were in NYHA functional class I-II.

Address for reprints:

Eduardo Salazar, M.D.

Instituto Nacional de Cardiología Ignacio Chávez

Juan Badiano No. 1. Col. Sección XVI

México, D.F. 14080

e-mail: edsalazar00@yahoo.com

Received: August 8, 2003

Accepted with revision: March 12, 2004
Conclusion: In a selected patient population, AVR in the elderly is associated with acceptable mortality and morbidity. The outlook for hospital operative survivors is excellent with improved quality of life and an expected survival normal for this particular age.

Key words: elderly, aortic stenosis, aortic valve replacement

\section{Introduction}

The life-span of the world population has increased progressively over the past half-century. As a result, the segment of the population, aged $\geq 70$ years, has been rapidly expanding. With the aging of the population, the degenerative diseases, particularly cardiovascular disease, are becoming increasingly frequent.

As symptomatic heart disease affects the elderly, the need for cardiac operations in this population continues to grow. Advances in anesthetic and surgical techniques, as well as better perioperative care, have resulted in a significant improvement in perioperative and long-term outcome after cardiac surgery in these patients. Degenerative calcifying aortic lesions are extremely common in elderly persons. Furthermore, these lesions constitute a progressive disease with a grim prognosis. ${ }^{1,2}$ Aortic valve replacement (AVR) is the only effective treatment for severe aortic valvular disease. The purpose of the present retrospective study was to evaluate the results of AVR in patients aged $\geq 70$ years operated at our institution.

\section{Patients and Methods}

The study series comprises 117 patients aged $\geq 70$ years who underwent AVR at our institution between January 1, 1991, and January 1, 2002. Data were obtained by retrospective review of medical records, echocardiograms, catheterization and coronary artery findings, perioperative data, and pathology reports.

M-mode, two-dimensional, and Doppler echocardiography were performed preoperatively in all patients. Echocardiographic data were not available in six patients. Retrograde left heart catheterization and coronary arteriography were also ob- 
tained in all patients. In 13 cases (11.1\%) it was not possible to obtain access to the left ventricle. Coronary artery disease was defined as a reduction of an epicardial vessel diameter by at least $50 \%$ in one view.

All patients were operated on by the same surgical team. Aortic valve replacement was performed using standard cardiopulmonary bypass technique. Surgical mortality was defined as occurring during hospitalization or within the 30 days following surgical intervention. Pathology reports were available for all explanted valves. Chronic anticoagulation with coumarin derivatives was maintained in all patients with a mechanical valve. Patients with bioprosthesis were placed in oral anticoagulant therapy for the first 3 months. Anticoagulation was continued indefinitely when atrial fibrillation was present. Follow-up data were obtained by retrospective review of the records registered at the outpatient department. Occasionally, the information was obtained by telephone contact with the patient or a family member.

\section{Statistical Analysis}

Student's $t$-test for continuous data and chi-square test for discrete variables were used to screen variables in the univariate analysis. Data consisting of 51 pre- and perioperative risk factors were analyzed as possible predictors of perioperative and late mortality. To determine the independent predictors of mortality, variables considered marginally significant $(\mathrm{p} \leq$ 0.05 ) in the univariate analysis were entered as covariates in a multivariate stepwise logistic regression model. Survival rates were estimated according to the method of Kaplan-Meier. Actuarial point estimates are given as percentages with $95 \%$ confidence interval (CI). Data collected were analyzed with the aid of SPSS version 10.0 software package (Statistical Package for Social Sciences, SPSS, Inc., Chicago, Ill., USA).

\section{Results}

\section{Clinical Characteristics of the Study Group}

The clinical characteristics of the 117 patients (72 men [61.5\%], 45 women [38.5\%], with a mean age of $73.8 \pm 3.5$ years; 11 [9.4\%] octogenarians) are listed in Table I. The vast majority of the patients had severe aortic stenosis or combined severe aortic stenosis and mild regurgitation $(\mathrm{n}=108$, $92.3 \%$ ); only $7.7 \%$ of the patients had pure severe aortic regurgitation. Valvular disease included calcific lesions in almost all patients (96.6\%), bicuspid valve (9.3\%), rheumatic disease ( $7.3 \%)$, bioprosthetic failure (2.6\%), and infective endocarditis (1.7\%).

Comorbid conditions were fairly common. Twenty-two patients (18.8\%) were in New York Heart Association (NYHA) functional class II and 73 patients (62.4\%) were in class III-IV (Table I). Significant coronary artery disease was present in 22 patients (18.8\%). Coronary artery bypass graft (CABG) procedures were performed in all these patients. Three patients (2.6\%) underwent concomitant mitral valve replacement.
TABLE I Clinical data in 117 patients aged $\geq 70$ years undergoing aortic valve replacement

\begin{tabular}{lc}
\hline Gender, $\mathrm{n}$ & $72(61.5)$ \\
Male & $45(38.5)$ \\
Female & $73.8 \pm 3.5$ \\
Age (years M \pm SD) & \\
Valvular lesions, $\mathrm{n}$ & $59(50.4)$ \\
Mixed aortic stenosis and regurgitation ${ }^{a}$ & $49(41.9)$ \\
Isolated aortic stenosis & $9(7.7)$ \\
Isolated aortic regurgitation & \\
Comorbidity, $\mathrm{n}$ & $63(53.8)$ \\
Smoking & $51(43.6)$ \\
Systemic hypertension & $38(32.5)$ \\
Chronic obstructive lung disease & $17(14.5)$ \\
Diabetes mellitus & $10(8.5)$ \\
Previous myocardial infarction & $9(7.7)$ \\
Atrial fibrillation & $5(4.3)$ \\
Chronic renal insufficiency & $4(3.4)$ \\
Previous cerebrovascular accident & $2(1.7)$ \\
Infective endocarditis & \\
Symptoms, $\mathrm{n}$ & $95(81.2)$ \\
Dyspnea & $73(62.4)$ \\
Heart failure & $51(43.6)$ \\
Angina pectoris & $25(21.4)$ \\
Syncope & $22(18.8)$ \\
NYHA class I & $22(18.8)$ \\
NYHA class II & $73(62.4)$ \\
NYHA class III-IV & \\
Coronary artery disease, $\mathrm{n}$ & $8(6.8)$ \\
Triple-vessel disease & $7(6.0)$ \\
Double-vessel disease & $7(6.0)$ \\
Single-vessel disease & \\
\hline Parentetica & \\
\hline
\end{tabular}

Parenthetical numbers are percents.

${ }^{a}$ Regurgitation less than $2 / 4$.

Abbreviations: $\mathrm{n}=$ number, $\mathrm{NYHA}=$ New York Heart Association.

A summary of the preoperative hemodynamic data in the 108 patients with pure or predominant aortic stenosis is listed in Table II. The systolic pressure gradient across the aortic valve was $\geq 50 \mathrm{mmHg}$ in 100 patients $(93.5 \%)$. Left ventricular ejection fraction was $\leq 35 \%$ in 10 patients $(9.6 \%)$. Twothirds of the patients $(63.1 \%)$ had an aortic valve area $\leq 0.6$ $\mathrm{cm}^{2}$. The seven patients with transaortic gradients $\leq 49 \mathrm{mmHg}$ underwent concomitant $\mathrm{CABG}$ or mitral valve replacement.

\section{Perioperative Data}

The valve model inserted depended on heart rhythm, contraindications to the use of anticoagulant therapy, and the preference of both the surgeon and the patient. The different types of prostheses used are listed in Table III.

Nine patients had severe isolated aortic regurgitation. Three of these had acute dysfunction of an aortic bovine pericardium prosthesis that had been implanted between 9 and 15 years previously. At surgery, the bioprostheses were calcified and each had a ruptured cusp. All nine patients had transvalvular 
TABLE II Hemodynamic assessment in 108 patients aged $\geq 70$ years undergoing aortic valve replacement for isolated aortic stenosis or for mixed aortic stenosis and mild regurgitation

\begin{tabular}{lcc}
\hline & $\mathrm{N}$ & $\mathrm{M} \pm \mathrm{SD}$ \\
\hline Aortic gradient (mmHg) & $107^{a}$ & $83.7 \pm 25.0$ \\
LV end-diastolic pressure (mmHg) & 88 & $17.7 \pm 9.1$ \\
LV ejection fraction (\%) & $104^{b}$ & $57.5 \pm 11.9$ \\
Aortic valve area (echo), $\mathrm{cm}^{2}$ & 84 & $0.6 \pm 0.2$ \\
Left atrial dimension, mm & 80 & $41.5 \pm 7.5$ \\
LV end- systolic dimension, mm & 83 & $34.8 \pm 9.0$ \\
LV end-diastolic dimension, mm & 87 & $49.0 \pm 8.1$ \\
Septum-diastolic thickness, mm & 78 & $14.5 \pm 2.7$ \\
LV posterior wall diastolic thickness, $\mathrm{mm}$ & 76 & $13.3 \pm 2.3$ \\
\hline
\end{tabular}

${ }^{a}$ Cath 91, echo 16.

${ }^{b}$ Cath 15, echo 89.

Abbreviations: $\mathrm{N}=$ number, $\mathrm{LV}=$ left ventricular, $\mathrm{SD}=$ standard deviation.

TABLE III Aortic valve prostheses implanted in 117 patients aged $\geq 70$ years

\begin{tabular}{lcc}
\hline & $\mathrm{N}$ & $\%$ \\
\hline $\begin{array}{l}\text { Bioprosthetic valves } \\
\text { Bovine pericardium }\end{array}$ & & \\
Porcine & 55 & \\
$\quad$ Total & 18 & \\
Mechanical valves & 73 & 62.4 \\
Bileaflet & & \\
Disc & 26 & \\
Ball & 14 & \\
Total & 4 & \\
\hline
\end{tabular}

${ }^{a}$ Three patients also received a mitral bovine pericardium bioprosthesis.

aortic pressure gradients $\leq 25 \mathrm{mmHg}$ and their ejection fraction ranged from 45 to $75 \%$. Eight patients were in NYHA functional class III-IV. There were no perioperative or late deaths in this group.

Table IV details the perioperative data. Almost one-half of the patients $(\mathrm{n}=58,49.6 \%)$ experienced no major perioperative complications. Seventeen patients (14.5\%) died within 30 days postoperatively. Among the 45 women in the series there were 9 deaths (20.0\%), whereas 8 of the 72 men $(11.1 \%$ ) died perioperatively. This difference in operative mortality between men and women was not statistically significant. Twelve of these patients (70.6\%) were in NYHA functional class III-IV. Two of the 22 patients $(9.1 \%$ ) who underwent AVR combined with CABG died, as did 1 of the 3 patients (33.3\%) with combined mitral valve replacement. Causes of death are listed in Table V. One of the two patients who died of sepsis had candida septicemia. The 14 patients requiring repeat surgery for excessive bleeding accounted for 8 of the hospital deaths, and of the 24 patients who developed acute renal insufficiency in the immediate postoperative period, 8 died.
TABLE IV Perioperative data in 117 patients aged $\geq 70$ years undergoing aortic valve replacement (AVR)

\begin{tabular}{lcc}
\hline & $\mathrm{N}$ & $\mathrm{M} \pm \mathrm{SD}$ \\
\hline Surgical procedure & & \\
AVR & $92(78.6)$ & \\
Concomitant CABG & $22(18.8)$ & \\
Concomitant MVR & $3(2.6)$ & $117.6 \pm 48.9$ \\
CP bypass time (min) & & $78.6 \pm 26.0$ \\
Aortic cross clamp time (min) & & $22.3 \pm 1.9$ \\
Aortic prosthesis size (mm) & & \\
Perioperative complications & & \\
Acute renal insufficiency & $24(20.5)$ & \\
Repeat surgery & $18(15.4)$ & \\
For bleeding & $14(12.0)$ & \\
For mediastintis & $3(2.6)$ & \\
For paraprosthetic leak & $1(0.9)$ & \\
Respiratory failure/infection & $17(14.5)$ & \\
Myocardial infarction & $4(3.4)$ & \\
Pericardial effusion & $2(1.7)$ & \\
Cerebrovascular accident & $3(2.6)$ & \\
Delirium & $10(8.5)$ & \\
Postoperative hospital stay (days ) & & \\
All patients & & \\
100 Survivors & & \\
\hline
\end{tabular}

Parenthetical numbers are percents.

Abbreviations: $\mathrm{AVR}=$ aortic valve replacement, $\mathrm{CABG}=$ coronary artery bypass graft, $\mathrm{MVR}=$ mitral valve replacement, $\mathrm{CP}=$ cardiopulmonary. Other abbreviations as in Table II.

TABLE V Causes of in-hospital death in 117 patients aged $\geq 70$ years undergoing aortic valve replacement

\begin{tabular}{lcc}
\hline & $\mathrm{N}$ & $\%$ \\
\hline Left ventricular pump failure & 6 & 5.1 \\
Respiratory failure/infection & 6 & 5.1 \\
Sepsis & 2 & 1.7 \\
Cardiac tamponade & 2 & 1.7 \\
Multiple organ failure & 1 & 0.9 \\
Total & 17 & 14.5 \\
\hline
\end{tabular}

Univariate analysis identified 7 pre- and perioperative risk factors associated with 30-day hospital mortality. In multivariate logistic regression analysis, only repeat surgery for bleeding $(\mathrm{p}=0.002)$, cardiopulmonary bypass time $(\mathrm{p}=$ $0.02)$, postoperative respiratory failure/infection $(\mathrm{p}=0.03)$, and postoperative acute renal insufficiency $(\mathrm{p}=0.02)$ remained statistically significant independent variables predictive of hospital mortality.

\section{Long-Term Follow-Up}

The actuarial survival curve of the 117 patients is shown in Figure 1A. The overall 5-year survival was 70.0\% (95\% CI 

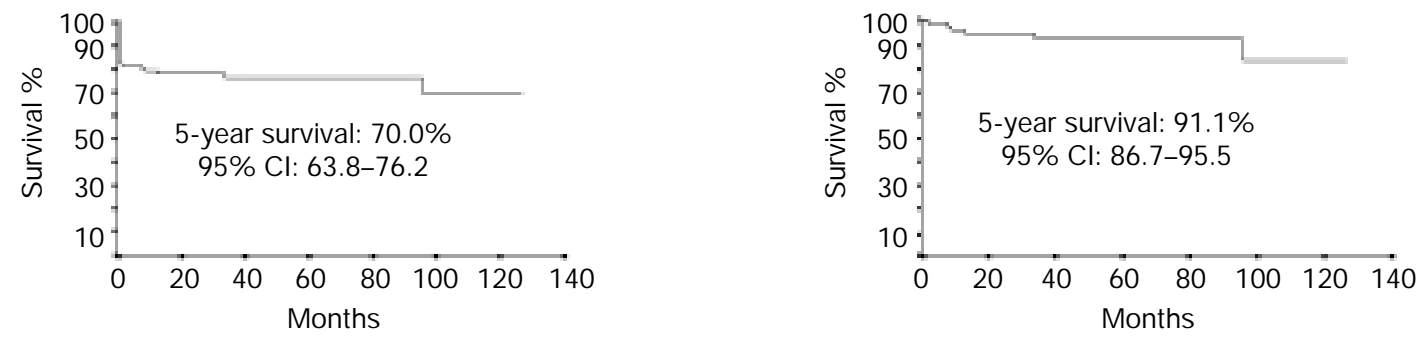

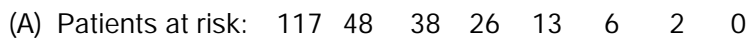

(B) Patients at risk: $\begin{array}{llllllll}78 & 48 & 38 & 26 & 13 & 6 & 2 & 0\end{array}$

FIG. 1 Actuarial (Kaplan-Meier) survival estimates: (A) from date of surgery for 117 patients in the study (including early deaths), and (B) for 78 hospital survivors included in follow-up. Numbers at bottom indicate patients at risk at beginning of periods.

63.8-76.2). Of the 100 patients who survived the operation, 22 were lost to follow-up. They had returned to their town of residence immediately after hospital discharge and reliable information could not be obtained. This group was essentially similar to that of 78 patients in whom follow-up data were available. Mean follow-up was $42.9 \pm 33.2$ months (range 2-127 months) for a total of 3,350 patient-months. Forty six patients $(59.0 \%)$ had received a bioprosthesis, while a mechanical valve had been implanted in the remaining 32 patients $(41.0 \%)$. Six patients died during this period. The causes of death are listed in Table VI; only two of these deaths were cardiac related. The actuarial survival for the 78 patients included in the follow-up is shown in Figure 1B. At 5 years, survival was $91.1 \%$ (95\% CI 86.7-95.5). None of the preoperative variables tested to predict long-term survival was found to correlate significantly with this endpoint. The clinical functional status of all patients surviving postoperative hospitalization showed significant improvement at follow-up evaluation. One year post surgery, $66(90.4 \%)$ patients were in NYHA functional class I and $7(9.6 \%)$ were in class II. Five years after surgery, all patients but one were in functional class I or II: $22(84.6 \%)$ patients were in class I, $3(11.5 \%)$ were in class II, and one (3.8\%) was in class III. Almost all patients had resumed normal activities for their age.

\section{Discussion}

Aortic stenosis is a potentially serious condition. Previous studies of natural history have shown a dismal outcome for pa-

TABLE VI Causes of mortality at follow-up study in 78 patients aged $\geq 70$ years who underwent aortic valve replacement $(n=6,7.7 \%)$

\begin{tabular}{lcc}
\hline Cause & Prosthesis & Months post-op \\
\hline Cerebral embolism & St. Jude & 9 \\
Chronic renal failure & Medtronic-Hall & 34 \\
Pneumonia & Medtronic-Hall & 2 \\
Leukemia & Hancock & 96 \\
Pancreatic cancer & Hancock & 8 \\
Infective endocarditis & Bovine pericardium & 13 \\
\hline
\end{tabular}

tients who were treated medically. Once a patient with aortic stenosis develops angina, syncope, dyspnea, or heart failure, the life expectancy in the absence of surgical correction is 1.5 to 3 years. ${ }^{1}$ Progression from mild to severe stenosis has been reported consistently and may be very rapid. A mean rate increase of the aortic gradient of 6.5 to $7 \mathrm{mmHg}$ per year has been found by serial cardiac catheterization and by Doppler echocardiographic studies. ${ }^{2}$

\section{Operative Results}

Aortic valve replacement is the only effective treatment for patients with severe aortic valve disease. Balloon aortic valvulotomy, used as an alternative treatment years ago, has been abandoned because of the high prevalence of restenosis and the high complication rate. ${ }^{3}$ The overall perioperative mortality of $14.5 \%$ in the present series is acceptable and comparable with the experience of other investigators. ${ }^{4-11}$ Most of these studies included a variable proportion of patients who underwent simultaneous CABG or an additional valve procedure. These concomitant procedures in elderly patients undergoing AVR are known to be related to a significant increase in operative mortality. ${ }^{4,7,8}$ In the present study, CABG was not associated with increased mortality, probably because of a small sample size. An evident and strong decrease in mortality after isolated AVR in the elderly has been reported recently; ${ }^{12-18}$ this may be attributed to better patient selection, refined myocardial protection, shorter cardiopulmonary bypass time, and improved surgical technique.

In multivariate logistic regression analysis, repeat surgery for excessive operative bleeding, prolonged cardiopulmonary bypass time, postoperative respiratory failure/infection, and postoperative acute renal failure were identified as independent predictors of hospital mortality. Excessive bleeding was noted in 14 patients $(12.0 \%)$ requiring reexploration. The prevalence of hemorrhage was similar to that in other studies. It has been reported that 5 to $15 \%$ of elderly patients undergoing AVR present with excessive bleeding requiring repeat surgery, and that this complication is associated with increased mortality. 7, 8, 10, 15, 19 Prolonged cardiopulmonary bypass times have also been found to be independent predictors of perioperative mortality in other studies. ${ }^{13,18}$ Respiratory infection and failure were responsible for one-third of the operative deaths in this 
series. Early extubation, aggressive institution of pulmonary physiotherapy, and early morbilization should be implemented in these patients, resulting in a significant reduction of ventilatory support time.

Several studies have documented that the operative mortality rates escalate with increasing age for patients undergoing AVR with or without concomitant CABG. ${ }^{5,9,19,20}$ These patients are at higher risk not only because of age, but also because of associated comorbidity. However, consideration for surgical intervention should not be made on the basis of age per se; instead, case selection should be based on life expectancy of each patient in terms of other disease factors.

Several studies have indicated that the operative risk of AVR in the elderly increases with the development of left ventricular dysfunction. ${ }^{8-12,15,18}$ However, unlike these studies, the indices of left ventricular dysfunction, such as ejection fraction $<35 \%$ and NYHA functional class III-IV, were not associated with increased operative mortality in the present study. There is no clear explanation for this finding. A few other studies have also found that NYHA functional class was unrelated to operative mortality in patients aged $\geq 70$ years $^{4}$ and in octagenarians. ${ }^{19}$

\section{Long-Term Outcome}

The overall 5-year survival rate for the 117 patients included in this series was $70.0 \%$ (95\% CI 63.8-76.2). Different studies have reported an overall 5-year survival of 60 to $70 \% .^{4-6,10,13,15,16}$ The outlook for this group of patients was excellent, with an expected survival normal for this particular age group and with good relief of symptoms. The actuarial survival rate at 5 years, in-hospital mortality excluded, of 91.1\% (95\% CI 86.7-95.5) is comparable with those of some series $^{8,11}$ and better than those of other studies reporting on hospital survivors. ${ }^{10,13,15-17}$ The most gratifying result in this study has been the improvement in these patients' quality of life, which is at least of equal importance as survival to the elderly. At 1 and 5 years of follow-up, $90 \%$ of the patients were asymptomatic and had resumed normal activities for their age. These results are consistent with those observed by others, ${ }^{15,17}$ who have evaluated the long-term functional recovery after AVR in patients aged $\geq 70$ years. They used quality of life assessment tools including the estimation of functional capacity, symptoms, and the patient's perception of total well being. Most of their patients stated that the operation had a significant impact on their health status and that they were functionally independent.

\section{Aortic Valve Selection for the Elderly}

Prosthesis selection for the elderly patient with aortic valve lesions has been a controversial issue. ${ }^{13}$ At the time of followup, no instance of structural bioprosthetic or mechanical valve failure was identified in any patient in the current study, and none of the patients had undergone repeat surgery for any cause of valve-related morbidity. There were no major bleeding episodes related to anticoagulation in the group of patients who received long-term anticoagulant therapy. It would appear that these patients can be managed with either type of valve with similar early and late risks as long as there are no specific contraindications to anticoagulant therapy. Nevertheless, it has been shown that structural aortic biological valve deterioration is essentially nonexistent at 10 and 12 years in patients aged $\geq 70$ years. ${ }^{21,22}$ This limited structural degeneration coupled with the infrequent need for coumarin anticoagulation would make the bioprosthesis the valve replacement of choice for the elderly patient with aortic valvular lesions. However, from our data, a categorical recommendation about a choice of prosthesis cannot be offered because our follow-up was limited to $42.9 \pm 33.2$ months. The presence of chronic atrial fibrillation should prompt indication of a mechanical valve.

\section{Conclusions}

Aortic valve replacement for severe aortic stenosis can be performed in selected elderly patients with increased but acceptable mortality and morbidity rates. It is the procedure of choice and the only effective treatment in this setting. The long-term outcomes of AVR are clearly better than the results of untreated aortic stenosis. In elderly patients, AVR produces significant lessening of symptoms and possibly increased longevity of those surviving hospitalization. The improvement in quality of life further emphasizes the value of surgical treatment of severe aortic stenosis in this age group. Elderly patients should not be denied AVR on the basis of age alone.

\section{References}

1. Ross J Jr, Braunwald E: Aortic stenosis. Circulation 1968;38(suppl): V61-V67

2. Faggiano P, Aurigemma GP, Rusconi C, Gaasch WH: Progression of valvular aortic stenosis in adults: Literature review and clinical implications. Am Heart J 1996;132:408-417

3. Dancy M, Dawkins K, Ward D: Ballon dilatation of the aortic valve: Limited success and early restenosis. Br Heart J 1989;60:236-239

4. Galloway AC, Colvin SB, Grossi EA, Baumann FG, Sabban YP, Esposito R, Ribakove GH, Culliford AT, Slater JN, Glassman E, Harty S, Spencer FC: Ten-year experience with aortic valve replacement in 482 patients 70 years of age or older: Operative risk and long-term results. Ann Thorac Surg 1990;49:84-93

5. Craver JM, Weintraub WS, Jones EL, Guyton RA, Hatcher CR: Predictors of mortality, complications, and length of stay in aortic valve replacement for aortic stenosis. Circulation 1988;78(suppl I):I-85-I-90

6. Azariades M, Fessler CL, Ahmad A, Starr A: Aortic valve replacement in patients over 80 years of age: A comparative standard for balloon valvuloplasty. Eur J Cardiothorac Surg 1991;5:373-377

7. Cullifortd AT, Galloway AC, Colvin SB, Grossi EA, Baumann FG, Esposito R, Ribakove GH, Spencer FC: Aortic valve replacement for aortic stenosis in persons aged 80 years and over. Am J Cardiol 1991;67: 1256-1260

8. Elayda MAA, Hall RJ, Reul RM, Alonzo DM, Gillette N, Reul GJ, Cooley DA: Aortic valve replacement in patients 80 years and older. Operative risks and long-term results. Circulation 1993;88(part 2):11-16

9. Logeais Y, Langanay T, Roussin R, Leguerrier A, Rioux C, Chaperon J, de Place C, Mabo P, Pony JC, Daubert JC, Laurent M, Almange C: Surgery for aortic stenosis in elderly patients. A study of surgical risk and predictive factors. Circulation 1994;90:2891-2898

10. Gehlot A, Mullany CJ, Ilstrup D, Schaff HV, Orszulak TA, Morris JJ, Daly RC: Aortic valve replacement in patients aged eighty years and older: Early and long-term results. J Thorac Cardiovasc Surg 1996;111:1026-1036 
11. Kolh P, Lahaye L, Gerard P, Limet R: Aortic valve replacement in the octogenarians. Perioperative outcome and clinical follow-up. Eur J Cardiothorac Surg 1999;16:68-73

12. Aranki SF, Rizzo RJ, Couper GS, Adams DH, Collins JJ, Gildea JS, Kinchla NM, Cohn LH: Aortic valve replacement in the elderly. Effect of gender and coronary artery disease on operative mortality. Circulation 1993;88(part 2): $17-23$

13. Davis EA, Grene PS, Cameron DE, Gott VL, Laschinger JC, Stuart RS, Sussman MS, Watkins L, Baumgartner WA: Bioprosthetic versus mechanical prostheses for aortic valve replacement in the elderly. Circulation 1996;94:(suppl II):II-121-II-125

14. Akins CW, Daggett WM, Vlahakes GJ, Hilgenberg AD, Torchiana DF, Madsen JC, Buckley MJ: Cardiac operations in patients 80 years old and older. Ann Thorac Surg 1997;64:606-615

15. Tseng EE, Lee CA, Cameron DE, Stuart RS, Greene PS, Sussman MS, Watkins L, Gardner TJ, Baumgartner WA: Aortic valve replacement in the elderly. Risk factors and long-term results. Ann Surg 1997;225:793-804

16. Asimakopoulos G, Edwards MB, Taylor KM: Aortic valve replacement in patients 80 years of age and older. Survival and cause of death based on 1100 cases: Collective results from the UK heart valve registry. Circulation 1997;96:3403-3408
17. Shapira OM, Kelleher RM, Zelingher J, Whalen D, Fitzgerald C, Aldea GS Shemin RJ: Prognosis and quality of life after valve surgery in patients older than 75 years. Chest $1997 ; 112: 885-894$

18. Milano A, Guglielmi C, De Carlo M, Di Gregorio O, Borzoni G, Verunelli F, Bortolotti U: Valve-related complications in elderly patients with biological and mechanical aortic valves. Ann Thorac Surg 1998;66(suppl): S82-S87

19. Olsson M, Granstrom L, Lindblom D, Rosenqvist M, Ryden L: Aortic valve replacement in octogenarians with aortic stenosis: A case-control study. JAm Coll Cardiol 1992;20:1512-1516

20. Tsai TP, Matloff JM, Chaux A, Kass RM, Lee ME, Czer LSC, DeRobertis MA Gray RJ: Combined valve and coronary artery bypass procedures in septuagenarians and octogenarians: Results in 120 patients. Ann Thorac Surg 1986;42:681-684

21. Jamieson WRE, Burr LH, Munro AI, Miyagishima RT, Gerein AN: Cardiac valve replacement in the elderly: Clinical performance of biological prostheses. Ann Thorac Surg 1989;48:173-185

22. Burr LH, Jamieson WRE, Munro AI, Miyagishima RT, Germann E: Porcine bioprostheses in the elderly: Clinical performance by age groups and valve positions. Ann Thorac Surg 1995;60:S264-S269 